\title{
METAPLASIA ÓSEA ENDOMETRIAL: REPORTE DE CASOS Y REVISIÓN DE LA LITERATURA
}

\author{
Osseous metaplasia of the endometrium: \\ case reports and literature review

\begin{abstract}
Alba Lucía Mondragón-Cedeño, M.D. *, Ángel David Miranda-Cruz, M.D.**, Sergio Augusto Parra-Duarte, M.D.***, Eliana Paredes-Becerra, M.D.****, Ana María Zúñiga-Chávez, M.D.*****
\end{abstract} \\ Recibido: octubre 19/10 - Aceptado: agosto 29/11
}

\section{RESUMEN}

Objetivo: presentar dos casos y revisar la literatura acerca de la etiología de la enfermedad y los métodos utilizados para su diagnóstico.

Casos clínicos: los casos fueron atendidos en el Hospital de San José, Hospital Universitario de referencia de tercer nivel de atención, a donde llegaron remitidas, por infertilidad y dolor pélvico crónico, dos pacientes. Sus ecografías mostraban imágenes hiperecogénicas en endometrio. Se les realizó histeroscopia, encontrando múltiples formaciones óseas flotantes en cavidad endometrial, extraídas con pinza grasper, cuyos cortes histológicos confirmaron el diagnóstico de metaplasia ósea endometrial. La primera mujer quedó en estado de embarazo 8 meses después de la intervención, finalmente tuvo un recién nacido a término sano. La segunda mujer inició dos embarazos que terminaron en abortos tempranos completos.

\footnotetext{
* Diplomado en Endoscopia Ginecológica de la FUCS y docente de la Universidad Libre Cali. Cali (Colombia). Correo electrónico: albamon@hotmail.com y albalucia.mondragon@imbanaco.com.co

** Coordinador Programa Endoscopia Ginecológica de la FUCS. Bogotá (Colombia).

*** Decano Facultad de Medicina de la FUCS. Bogotá (Colombia).

***** Residente Ginecología Universidad Libre Cali. Cali (Colombia).

****** Docente Endoscopia de la FUCS. Bogotá (Colombia).

El trabajo fue presentado en el X Congreso de Ia Sociedad Iberoamericana de Endoscopia Ginecológica e Imagenología SIAEGI, que se realizó en Cartagena (Colombia) del 24 al 30 de mayo de 2009, en la modalidad de trabajos libres, en la categoría de videos.
}

Materiales y métodos: se realizó una búsqueda electrónica en las bases de datos Medline vía PubMed, SciELO y Ovid, en donde se incluyeron artículos publicados en los últimos 15 años.

Conclusión: la metaplasia ósea es un problema de diferenciación celular, de las células madre estromales del endometrio secundario, a raíz de una deficiencia de superóxido dismutasa. Esta entidad se sospecha por ecografía transvaginal y se debe diagnosticar y tratar con histeroscopia.

Palabras clave: metaplasia ósea, osificación endometrial, ectopia ósea, infertilidad, histeroscopia, dolor pélvico crónico, hemorragia uterina anormal.

\section{SUMMARY}

Objective: presenting two cases and reviewing the pertinent literature concerning the methods used in diagnosing the entity and its etiology.

Clinical cases: the cases were attended in the third-level San José teaching hospital where they had been referred due to infertility and chronic pelvic pain. Their echographies revealed hyperechogenic images in the endometrium. Hysteroscopy was performed, revealing multiple osseous formations floating within the endometrial cavity; these were extracted with grasper tweezers and their histological sections confirmed a diagnosis of osseous metaplasia of the endometrium. The first 
woman became pregnant 8 months later, delivering a healthy newborn at full-term; the second woman became pregnant twice but her attempts ended in complete early abortions.

Materials and methods: a search was made of MEDLINE databases via PUBMED, SciELO and Ovid, including articles published during the last 15 years.

Conclusion: osseous metaplasia is a cause of infertility involving cellular differentiation of secondary endometrial stromal (stem) cells leading to superoxide dismutase deficiency; this is suspected by transvaginal echography (ultrasound) and should be diagnosed and treated with hysteroscopy.

Key words: osseous metaplasia, endometrial ossification, osseous ectopy, infertility, hysteroscopy, chronic pelvic pain, abnormal uterine hemorrhage.

\section{INTRODUCCIÓN}

La metaplasia ósea endometrial es una patología benigna poco frecuente, ${ }^{1,2}$ que consiste en la presencia de material óseo heterotópico en el interior de la cavidad uterina. ${ }^{3,4}$ Esta entidad fue descrita por primera vez hace 125 años, gracias a los grandes hallazgos realizados por Rudolf Virchow. Esta enfermedad ha sido identificada con múltiples denominaciones: endometritis calcificante, calcificación distrófica, hueso heterotópico, osificación endometrial y finalmente metaplasia ósea endometrial. ${ }^{1}$

$\mathrm{Su}$ frecuencia es tan baja que después de 116 años de su descripción, Feyles $\mathrm{V}$ y colaboradores ${ }^{5}$ encontraron reportados solamente 240 casos, estimando que ocurran 3 en cada 10000 mujeres, ${ }^{4}$ la mayoría entre 20 y 40 años, aunque no se excluye la ocurrencia en mujeres de mayor edad y posmenopáusicas. ${ }^{6}$

Por su baja prevalencia, algunos ginecólogos o médicos no conocen ésta enfermedad o no la sospechan, retardando así su diagnóstico y su adecuado manejo en mujeres con hemorragia uterina anormal, dolor pélvico crónico e infertilidad.
Se presentan dos casos confirmados por patología, con el objetivo de informar y hacer una revisión de la literatura, respecto a la etiología de la enfermedad y la utilidad de las pruebas que se utilizan para su diagnóstico.

\section{REPORTE DE CASOS}

El primer caso hace referencia a una mujer de 25 años G1A1, con infertilidad secundaria de 7 años de evolución. La paciente había presentado un legrado obstétrico por aborto, hace 5 años, además, presentaba dismenorrea y dispareunia. A través de una ecografía pélvica transabdominal y transvaginal se observaron, en el endometrio, imágenes hiperrefringentes irregulares (figura 1), por lo cual fue remitida al Hospital de San José, hospital privado de tercer nivel de atención ubicado en Bogotá (Colombia), con sospecha de metaplasia ósea, allí se le realizó histeroscopia operatoria en sala de cirugía, utilizando un instrumento tipo Bettocchi. Se encontraron fragmentos óseos que fueron extraídos con pinza grasper y enviados al laboratorio de patología, donde la visión microscópica confirmó la impresión diagnóstica clínica y quirúrgica de metaplasia ósea endometrial (figura 2). Ocho meses después del procedimiento quirúrgico, la paciente quedó en estado de embarazo, terminando la gestación con un recién nacido sano, de sexo masculino y nacido vía cesárea.

Figura 1. Imágenes ecográficas hiperrefringentes típicas de metaplasia ósea endometrial.

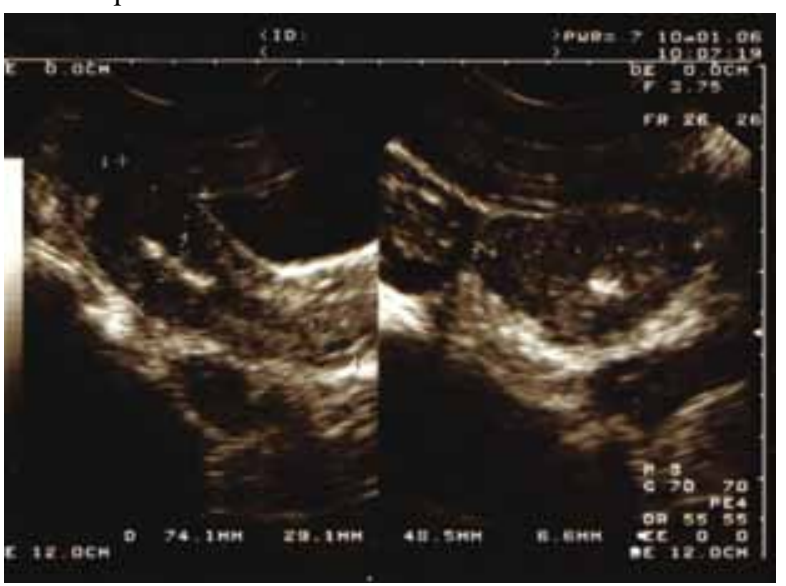


Figura 2. Tejido óseo rodeado de endometrio funcional, observado en los cortes histopatológicos que confirman el diagnóstico de metaplasia ósea endometrial.

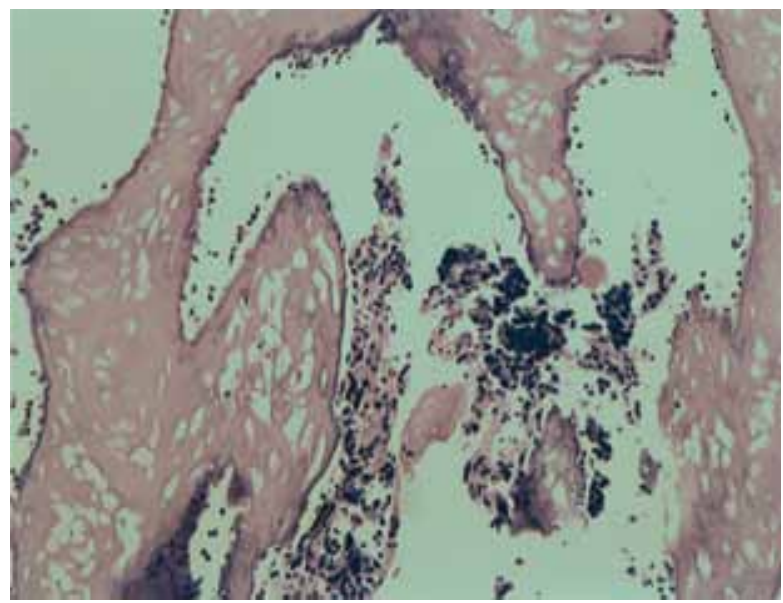

El segundo caso hace alusión a una paciente de 32 años G1P1, con infertilidad secundaria de 5 años de evolución, acompañada de dolor pélvico crónico y hemorragia uterina anormal. La paciente quedó en estado de embarazo a los 16 años cuyo parto fue normal y no presentó antecedentes de abortos. Tres años antes, mediante una ecografía pélvica, se observaron imágenes hiperecoicas en endometrio, las cuales fueron interpretadas como cuerpo extraño en cavidad tipo dispositivo intrauterino (DIU); razón por la cual fue llevada a cirugía para extracción bajo anestesia. En ese acto quirúrgico se realizó legrado uterino y no se encontró el dispositivo. Posteriormente en una nueva ecografía pélvica transvaginal, se observó persistencia de los ecos densos centrales, se descartó la posibilidad de dispositivo con una radiografía simple de pelvis y se remitió con la sospecha de metaplasia ósea. A la paciente se le practicó una histeroscopia operatoria, en la sala de cirugía del Hospital de San José, encontrando fragmentos óseos de las características vistas en las figuras $\mathbf{3}$ y $\mathbf{4}$. Los fragmentos fueron extraídos con pinza grasper, a través del canal operatorio del histeroscopio tipo Bettocchi. Los cortes en patología y la visión microscópica de los fragmentos de tejido óseo confirmaron la impresión
Figura 3. Formaciones óseas blancas, pequeñas, flotantes, en cavidad endometrial patognomónica de metaplasia ósea endometrial, apreciadas en la histeroscopia.

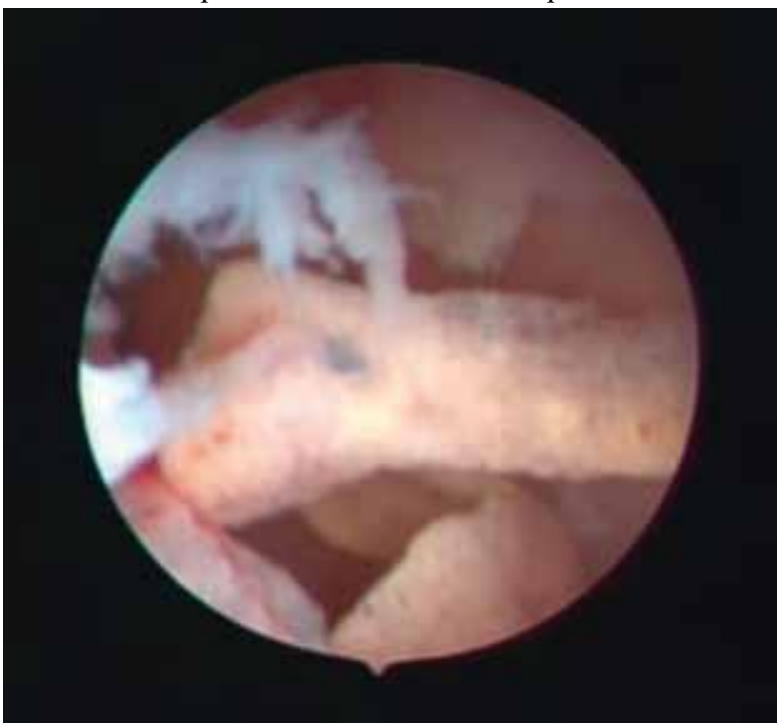

Figura 4. Formaciones óseas coraliformes, flotantes en cavidad uterina, 'arrecife de coral, ' observadas en histeroscopia sugestivas de metaplasia ósea endometrial.

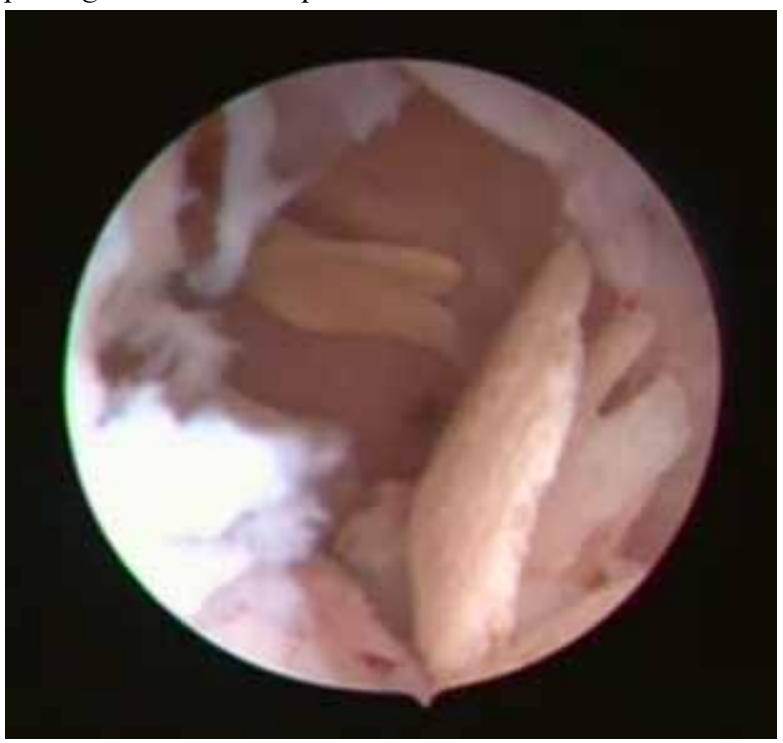

diagnóstica clínica y quirúrgica de metaplasia ósea endometrial. Posterior al procedimiento, la paciente refirió completa disminución del dolor, además, se evidenció la desaparición de imágenes endouterinas calcificadas. Finalmente la paciente inició dos embarazos que terminaron en aborto completo temprano. 


\section{MATERIALES Y MÉTODOS}

Se realizó una revisión sistemática de la literatura en las bases de datos Medline vía PubMed, SciELO y Ovid, utilizando las palabras clave: osseous metaplasia, endometrial ossification y osseous ectopia. De 76 artículos publicados en los últimos 15 años, se escogieron publicaciones de texto completo, que estuvieran escritos en español o inglés, que hicieran énfasis en la etiología de la enfermedad y en la utilidad de las pruebas que se utilizan para su diagnóstico.

\section{DISCUSIÓN}

La mayoría de los autores coinciden en afirmar que el 80\% de los casos de metaplasia ósea endometrial ocurre después de un embarazo, o tienen como antecedente aborto con dilatación y curetaje,${ }^{6-8} \sin$ embargo, existen reportes de asociación con: biopsia de endocérvix, DIU, instrumentación endometrial y conización, LETTZ de cérvix. ${ }^{5}$

Las manifestaciones clínicas frecuentemente reportadas incluyen: infertilidad, dolor pélvico crónico, dismenorrea, dispareunia y sangrado uterino anormal. ${ }^{1,2,6,8}$ Pocas veces ocurre expulsión de los fragmentos óseos por vía vaginal, cuando esto sucede, este hecho constituye un signo patognomónico. ${ }^{1}$ Puede cursar también en forma asintomática. ${ }^{3,4}$

Los reportes de la literatura no informan valores de sensibilidad y especificidad sobre los métodos utilizados para el diagnóstico de la entidad. Teniendo en cuenta esta aclaración metodológica, los autores realizan el acercamiento a su diagnóstico utilizando:

1. Ultrasonografía transvaginal: es el método habitualmente reportado en la literatura. Con este procedimiento la imagen fonográfica, que generalmente se observa, es la de una banda alargada refringente hiperecogénica intrauterina, que sigue el eje longitudinal de dicho órgano, ${ }^{1,4}$ con proyección de sombra acústica posterior ${ }^{3,4}$ muy similar a la que se observa ante la presencia de un dispositivo intrauterino DIU, en la cavidad uterina; ${ }^{1}$ y muy ocasionalmente parecida al síndrome Asherman. ${ }^{5}$ Se diferencia del dispositivo intrauterino por la ausencia de su imagen en una radiografía simple anteroposterior de pelvis.

2. Histerosalpingografía: a través de este procedimiento se puede encontrar una cavidad uterina de bordes irregulares, y pequeños defectos de llenado similares a los observados cuando hay sinequias intrauterinas. ${ }^{8}$

3. Histeroscopia: es un procedimiento clínico a través del cual se observan imágenes patognomónicas, es considerado, además, como un método de elección ya que permite extraer los fragmentos a partir del tratamiento. ${ }^{3}$ En la visión histeroscópica se describen dos imágenes características: la primera de placas delgadas con bordes dentados, de aspecto coraliforme, radiado, o en abanico, enclavadas en el endometrio pero sin integrarse a él, con un aspecto muy similar a un "arrecife de coral" (figura 3); la segunda de formaciones blancas, de pequeño tamaño, superficies lisas y de límites precisos (figura 4). ${ }^{4}$

4. Histopatología o biopsia: es el diagnóstico definitivo donde se reporta tejido óseo con osteoblastos, predominantemente de tipo esponjoso o trabecular, rodeado de endometrio funcional, a veces con infiltrado inflamatorio intraplasmocitario y áreas de necrosis focal (figura 2). Este material óseo contiene abundantes espacios medulares intertrabeculares, los cuales se encuentran ocupados por restos de tejido endometrial con infiltrado inflamatorio. ${ }^{1}$ En mujeres de mayor edad, se debe diferenciar de la formación de hueso observada en tumores malignos mixtos de origen mulleriano y en teratomas. ${ }^{6}$ Además, se debe realizar biopsia de endometrio para buscar y tratar posibles estimuladores de la formación de radicales libres. ${ }^{3,5}$

Después de la cirugía se recomienda ultrasonografía pélvica, ya que algunos fragmentos, que pueden no ser identificados en la histeroscopia, 
suelen ser embebidos por el endometrio o el miometrio. ${ }^{1,4}$ Con un manejo ágil y adecuado de la entidad, las pacientes alcanzarán una disminución total de la sintomatología y lograrán recobrar su fertilidad. ${ }^{9,10}$

\section{Etiología}

En el pasado se postularon varias hipótesis sobre la etiología de la enfermedad, ${ }^{7}$ sin embargo, solo hasta hace muy pocos años se logró confirmar que la presencia de material óseo heterotópico, en el interior de la cavidad uterina, es producto de la transformación del tejido endometrial en el tejido óseo, que se lleva a cabo de manera endógena. ${ }^{3,4,8}$ La prueba de que ese tejido óseo es originado desde las células del mismo huésped fue recientemente demostrada por Cayuela E y colaboradores, con técnicas de PCR de ADN. ${ }^{4,11}$ Pese a todo lo anterior, la entidad debe diferenciarse de la retención prolongada de huesos fetales que presentan reacción tisular alrededor de las partículas y osificación endocondral. ${ }^{12}$

Las células que originan ese cambio son las células madres totipotenciales y las células de reserva mesenquimales pluripotenciales, localizadas en la capa basal del endometrio, cuya función fisiológica normal es iniciar la regeneración del endometrio tras la menstruación por un proceso de metaplasia escamosa. ${ }^{13}$ Se ha descrito que la alteración en la diferenciación celular es producto de una grave disfunción metabólica de estas células secundarias que se traduce en un aumento de los radicales libres intracelulares. $^{2}$

Los radicales libres son moléculas libres de oxígeno (ROS): radicales hidroxilo $(\mathrm{OH})$, aniones superóxido $\left(\mathrm{O}_{2}^{-}\right)$, y peróxido de hidrógeno $\left(\mathrm{H}_{2} \mathrm{O}_{2}\right)$, que se producen durante el metabolismo aerobio, como respuesta a estímulos externos e internos y que en altas dosis dan lugar a estrés oxidativo. ${ }^{14}$ Existe una gran variedad de sistemas de defensa antioxidante, tanto enzimáticos como no enzimáticos, que se coordinan cooperativamente y protegen al organismo de los riesgos que conlleva el estrés oxidativo. Entre ellos se destacan: las actividades enzimáticas superóxido dismutasa (SOD), glutatión peroxidasa (GPX), catalasa (CAT) y glutatión (GSH); además del ácido ascórbico (vitamina $\mathrm{C}$ ), alfa-tocoferol (vitamina E), beta-caroteno, vitamina A, flavonoides y ácidos fenólicos. ${ }^{14} \mathrm{La}$ enzima superóxido dismutasa (SOD) ${ }^{15}$ descubierta por McCornd y Fridovich en 1969, es considerada la primera fase de defensa antioxidante, ya que cataliza la reacción de destrucción de los radicales superóxido $\left(\mathrm{O}_{2}^{-}\right)$mediante su transformación en peróxido de hidrógeno, que se destruye a su vez por las actividades de la catalasa o el glutatión peroxidasa. ${ }^{14}$ Se ha reportado deficiencia en la actividad de ésta enzima en endometrios de mujeres con la entidad objeto de estudio. ${ }^{16} \mathrm{Se}$ postula entonces que en endometrios que han aumentado la formación de radicales libres ya sea por lesiones, retención de tejidos, inflamación crónica posaborto o infecciones, la deficiencia en la actividad de esta enzima produciría una falla en la defensa antioxidante ${ }^{2}$ conduciendo a un estrés oxidativo de sus células.

En las células madre estromales, que se encuentran allí, este fenómeno biomolecular alteraría su capacidad de diferenciación celular, ${ }^{2}$ transformándolas, inicialmente, en fibroblastos y luego en osteoblastos, ${ }^{1,2,6}$ los cuales bajo el estímulo de factores de crecimiento inician el proceso de osteogénesis, formando la matriz ósea que se mineraliza dando lugar a las trabéculas óseas y al hueso esponjoso. ${ }^{2}$ Lo que parece no estar suficientemente claro es por qué si el aborto es tan frecuente, este evento es relativamente inusual, lo que lleva a pensar que debe existir, en las mujeres que lo padecen, algún defecto genéticamente no identificado aún o algunos factores predisponentes o disparadores. De acuerdo a esta evidencia, la etiología de esta entidad sería la deficiencia en el endometrio de la actividad de la enzima protectora superóxido dismutasa (SOD). ${ }^{2}$ 


\section{CONCLUSIÓN}

La metaplasia ósea es un problema de diferenciación celular de las células madre estromales del endometrio, que se desencadena a partir del estrés oxidativo generado por la deficiencia de la actividad de la enzima superóxido dismutasa. Se sospecha por ecografía transvaginal, se diagnostica y se trata con histeroscopia. Se debe realizar biopsia de endometrio para buscar y tratar posibles estimuladores de la formación de radicales libres. Con un manejo ágil y adecuado, las pacientes pueden reducir totalmente su sintomatología y recuperar la fertilidad.

\section{REFERENCIAS}

1. Peña D, Martínez A. La metaplasia ósea del endometrio como causa de esterilidad. Su manejo histeroscópico. Reporte de un caso. En: Monografias.com. Visitado 2011 May 16. Disponible en: http://www.monografias. com/trabajos 33/metaplasiaoseaendometrio/ metaplasia-osea-endometrio.shtml

2. Bahçeci M, Demirel LC. Osseous metaplasia of the endometrium: a rare cause of infertility and its hysteroscopic management. Hum Reprod 1996;11:2537-9.

3. Corvalán J, Sanhueza P. Metaplasia ósea endometrial: con sospecha diagnóstica ecográfica o histeroscópica. Rev Chil Obstet Ginecol 2002;67:30-3.

4. Vásquez $\mathrm{H}$, Martínez $\mathrm{O}$, Triana J. Metaplasia ósea como causa de infertilidad secundaria. Rev Obstet Ginecol Venez 2003;63:157-60.

5. Feyles V, Moyana TN, Pierson RA. Recurrent pregnancy loss associated with endometrial hyperechoic areas (endometrial calcifications): a case report and review of the literature. Clin Exp Obstet Gynecol 2000;27:5-8.

6. Shimizu M, Nakayama M. Endometrial ossification in a postmenopausal woman. J Clin Pathol 1997;50:171-2.
7. Gómez P, Beltrán L, Sánchez L, Metaplasia ósea endometrial: reporte de un caso. Rev Colomb Obstet Ginecol 1997;48:199-201.

8. Demeterco CP, Murata MK, Cequinel MG, Cornel CA, Francisco JF, Beduschi AF. Endometrial osseous metaplasia and primary infertility. Rev Bras Ginicol Obstet 2001;23:119-21.

9. Bravo E, Haberland J. Metaplasia ósea del endometrio como causa de infertilidad. Rev Chil Obstet Ginecol 2002;67:381-3.

10. Coccia ME, Becattini C, Bracco GL, Scarselli G. Ultrasound-guided hysteroscopic management of endometrial osseous metaplasia. Ultrasound Obstet Gynecol 1996;8:134-6.

11. Cayuela E, Perez-Medina T, Vilanova J, Alejo M, Cañadas P. True osseous metaplasia of the endometrium: the bone is not from a fetus. Fertil Steril 2009;91:1293.e1-4.

12. Tulandi T, Al-Sunaidi M, Arseneau J, Tonin PN, Arcand SL. Calcified tissue of fetal origin in utero. Fertil Steril 2008;89:217-8.

13. Vizoso F. Celulas madres uterinas. Visitado 2011 May 16. Disponible en: http://unahistoriaclinica.blogspot. com/2009/10/celulas-madre-uterinas-como-cura-de. html.

14. Aleman L. Principales enzimas antioxidantes. En: Monografias.com. Visitado 2011 May 16. Disponible en: http://www.monografias.com/trabajos24/enzimasantioxidantes/enzimas-antioxidantes.shtml

15. Nevarez Bernal R, Vilchis Nava P, Kably Ambe A. Osificación endometrial: comunicación de cuatro casos y revisión bibliográfica. Ginecol Obstet Mex 2007;75:168-71.

16. Sugino $\mathrm{N}$, Shimamura K, Takiguchi S, Tamura H, Ono $\mathrm{M}$, Nakata $\mathrm{M}$, et al. Changes in activity of superoxide dismutase in the human endometrium throughout the menstrual cycle and in early pregnancy. Hum Reprod 1996;11:1073-8. 